INFECTIOUS

DISEASE

CLINICS

of North America

Infect Dis Clin N Am 17 (2003) 615-634

\title{
Intracellular pharmacodynamics of antibiotics
}

\author{
Stéphane Carryn, PharmD, PhD, \\ Hugues Chanteux, PharmD, PhD, \\ Cristina Seral, PharmD, PhD, \\ Marie-Paule Mingeot-Leclercq, PharmD, PhD, \\ Françoise Van Bambeke, PharmD, PhD, \\ Paul M. Tulkens, MD, PhD*
}

Unité de Pharmacologie Cellulaire et Moléculaire, Université Catholique de Louvain, UCL 73.70 Avenue E. Mounier 73, Brussels B-1200, Belgium

Treatment of intracellular bacterial infection remains both a medical and economic challenge. Pathogens thriving or maintaining themselves in cells, or simply taking transient refuge therein, are indeed shielded from many of the humoral and cellular means of defense. They also seem more or less protected against many antibiotics. This explains why intracellular bacteria not only are harmful for the host cells but may also constitute a reservoir for recurrence and reinfection. Because antibiotics poorly act on intracellular bacteria, selection of resistant mutants may also be fostered. All these considerations stress the importance of understanding (1) whether and to what extent antibiotics may or may not act against intracellular bacteria, (2) which are the pharmacokinetic and pharmacodynamic parameters governing their activity, and (3) how chemotherapy can be improved on that basis. This article examines these issues starting from basic knowledge about the disposition of bacteria and antibiotics in cells and moving to an integration

Stéphane Carryn is Boursier of the Belgian Fonds de Formation à la Recherche dans l'Industrie et l'Agriculture. Hugues Chanteux is Aspirant, and Françoise Van Bambeke Chercheur qualifié of the Belgian Fonds National de la Recherche Scientifique. The experimental work of the authors illustrated here has been supported by the Belgian Fonds de la Recherche Scientifique Médicale (grants no. 3.4549 .00 and 3.4.612.00) and by grants-in-aid from Eli Lilly \& Co. and Bayer AG.

* Corresponding author.

E-mail address: tulkens@facm.ucl.ac.be (P.M. Tulkens). 
of these concepts to rationalize the various but quite often contradictory experimental observations concerning intracellular activity.

\section{Entry and fate of bacteria in cells}

Antibiotics must reach and bind to their target to exert their chemotherapeutic activity. A prerequisite is that bacteria and antibiotics come into contact. Knowing where bacteria are in cells is critical. A large body of data has now been obtained in this context and is presented in a pictorial fashion in Fig. 1. The two main points to be stressed here are that the fate of bacteria is highly variable according to the pathogen considered and critically influenced

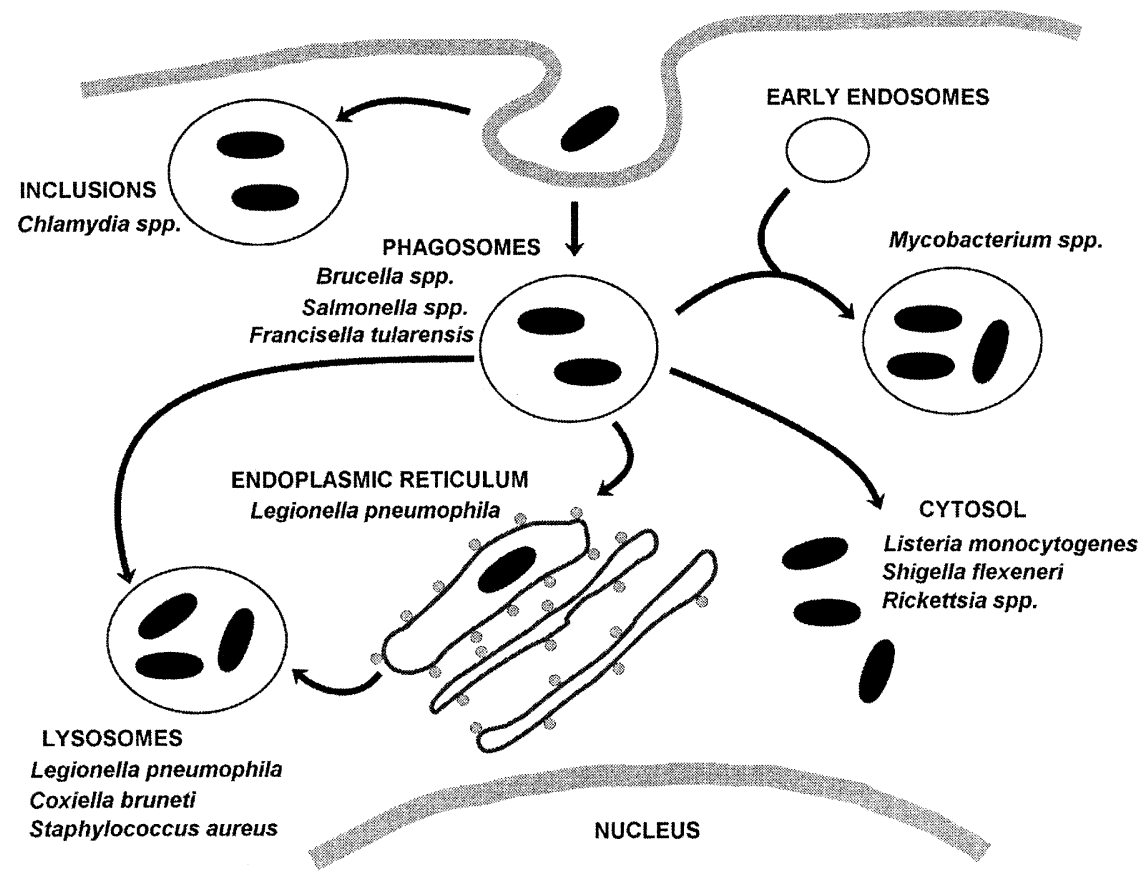

Fig. 1. Pictorial description of the various pathways followed by intracellular bacteria to evade cellular mechanisms of destruction after phagocytosis. Some bacteria (eg, Listeria, Shigella, Rickettsiae) escape from phagosomes early on after having been engulfed and avoid both acidification and subsequent sequestration in phagolysosomes. Others remain in phagosomes that continue to fuse with newly formed endosomes but not with lysosomes (Mycobacteriae); in phagosomes that are made unable to fuse with other vacuoles (Brucellae, Salmonellae, Francisella); or in phagosomes that are turned into specialized entities (Chlamydiae). In some cases (Legionella), phagosomes containing living bacteria may fuse with the endoplasmic reticulum in a form of abnormal autophagy. Finally, certain bacteria ( $S$ aureus, Coxiella, and to some extent Legionella) may simply resist the fusion of phagosomes with lysosomes and multiply within phagolysosomal vacuoles. 
by its capacity to express virulence factors; and most of the pathways taken by bacteria are actually diversions from the common process of phagocytosis, the function of which is to convey particulate matters, such as bacteria, from the extracellular milieu to lysosomes and related digestive vacuoles. These diversions are geared at allowing the virulent bacteria to evade the defense mechanisms associated with phagocytosis (a pathogen is a microorganism capable of evading lysosomal destruction) [1]. Table 1 shows in a summarized fashion the present state of knowledge concerning a selected number of obligate and facultative pathogens concerning their main target cells and their prevailing subcellular localization. These various niches not only allow bacteria to be protected from the extracellular environment but they also provide distinct physicochemical conditions that affect both the bacteria and the activity of antibiotics. In their way to lysosomes, bacteria are also exposed to reactive oxygen nitrogen intermediates generated by the host NADPH oxidase [2] and nitric oxide synthase [3]. Moving to the cytosol is one way to escape those mechanisms to gain access to a neutral medium probably rich in growth-promoting factors. This may explain why some bacteria have developed quite sophisticated techniques to achieve this as quickly as possible. Those bacteria, like Listeria monocytogenes, multiply actively once having reached the cytosol (interferon- $\gamma$ maintains Listeria in phagosomes and lysosomes and thereby limits severely its multiplication [4] because of continuing exposure to oxygen and nitrogen reactive species [5]). Bacteria

Table 1

Main intracellular bacteria with predominant target cells in humans and known subcellular localization of virulent forms

\begin{tabular}{|c|c|c|c|c|}
\hline Organism & $\begin{array}{l}\text { Type of } \\
\text { parasite }\end{array}$ & Target cells & $\begin{array}{l}\text { Subcellular } \\
\text { localization }\end{array}$ & References \\
\hline Brucella spp & Facultative & Macrophages & Phagosomes & [99] \\
\hline Chlamydia spp & Obligate & Lung parenchyma cells & Inclusions & [100] \\
\hline Coxiella brunetii & Obligate & $\begin{array}{l}\text { Macrophages, } \\
\text { lung parenchyma cells }\end{array}$ & $\begin{array}{l}\text { Phagosomes, } \\
\text { phagolysosomes }\end{array}$ & {$[101,102]$} \\
\hline $\begin{array}{l}\text { Francisella } \\
\quad \text { tularensis }\end{array}$ & Facultative & Macrophages & Phagosomes & {$[103]$} \\
\hline $\begin{array}{l}\text { Legionella } \\
\quad \text { pneumophila }\end{array}$ & Facultative & Macrophages & $\begin{array}{c}\text { Endoplasmic } \\
\text { reticulum, } \\
\text { lysosomes }\end{array}$ & {$[102,104]$} \\
\hline $\begin{array}{l}\text { Listeria } \\
\quad \text { monocytogenes }\end{array}$ & Facultative & $\begin{array}{r}\text { Macrophages, } \\
\text { hepatocytes }\end{array}$ & Cytosol & [4] \\
\hline $\begin{array}{l}\text { Mycobacterium } \\
\text { tuberculosis }\end{array}$ & Facultative & Macrophages & Early endosomes & {$[105]$} \\
\hline Rickettsia spp & Obligate & Endothelial cells & Cytosol & {$[106]$} \\
\hline Salmonella spp & Facultative & Macrophages & Phagosomes & [107] \\
\hline Shigella flexeneri & Facultative & Macrophages & Cytosol & [108] \\
\hline $\begin{array}{l}\text { Staphylococcus } \\
\quad \text { aureus }\end{array}$ & Opportunist & Macrophages, PMNs & Phagolysosomes & [109-111] \\
\hline
\end{tabular}


that gain access to phagolysosomes have a different fate. Generally speaking, lysosomes and phagolysosomes can be considered as acidic compartments poor in nutrients (iron depletion [6], tryptophan degradation [7]). The consequence is that intracellular bacteria that sojourn in those vacuoles tend to become partially dormant. This reduces their sensitivity to many antibiotics. These bacteria also are confronted with potent lytic enzymes and specific antimicrobial agents, such as defensins [8]. Unfortunately, little is known about the cooperation (or hindrance) between these factors and antibiotics. One may suspect, however, that the reduction of bacterial metabolism induced by these agents could also decrease their sensitivity to antibiotics.

\section{Cellular uptake and disposition of antibiotics (cellular pharmacokinetics)}

Table 2 shows the key cellular pharmacokinetic properties of antibiotics that have been studied so far. As for the bacteria, one is struck by the diversity of behaviors, which is not so much of a surprise in view of the large difference in molecular structures among antibiotic classes. Common properties can, however, be delineated at the pharmacochemical class level as is reviewed here.

\section{$\beta$-Lactams}

All studies have so far reported a lack of accumulation (ie, an apparent intracellular concentration lower than the extracellular one at equilibrium) for all $\beta$-lactams whether in phagocytic [9-15] or nonphagocytic cells and tissues in general [16]. It has often been concluded that $\beta$-lactams are unable to penetrate cells, which is probably incorrect because most of the representatives of this class of drug do diffuse reasonably well through biologic membranes. All $\beta$-lactams display a free carboxylic function (or an equivalent proton-donor group), which is essential for their activity [17,18]. Modeling studies of the transmembrane distribution of weak acids show that the total concentration of such substances is always lower in acidic than in basic or neutral membrane-bounded compartments [19]. Because the cell cytosol is more acidic than the extracellular milieu, single acid $\beta$-lactams are prevented from accumulating in cells even if they can pass across membranes. Masking the free carboxyl group of a single acid $\beta$-lactam, such as penicillin $\mathrm{G}$, by a basic moiety is actually all that is needed to allow substantial accumulation of the corresponding derivative [13]. The situation may be more complex for zwitterionic $\beta$-lactams, such as ampicillin, or most of the third- and fourth-generation cephalosporins, but none of them has ever been shown to accumulate in cells. One additional reason could be the presence of antibiotic efflux pumps that could actively extrude $\beta$-lactams from cells $[20,21]$. 
Table 2

Influx, accumulation levels (at equilibrium), efflux, and predominant subcellular localization of the main antibiotics (grouped by pharmacochemical classes)

\begin{tabular}{|c|c|c|c|c|c|}
\hline $\begin{array}{l}\text { Pharmacochemical } \\
\text { class }\end{array}$ & Antibiotic & Influx $^{a}$ & Efflux $^{\mathrm{a}}$ & $\begin{array}{l}\text { Accumulation } \\
\text { level (at } \\
\text { equilibtrum) }\end{array}$ & $\begin{array}{l}\text { Predominant } \\
\text { subcellular } \\
\text { localization }\end{array}$ \\
\hline$\beta$-Lactams & All & Fast & Variable & $<1$ & Cytosol \\
\hline \multirow[t]{4}{*}{ Macrolides } & Erythromycin & Fast & Fast & $4-10$ & $\begin{array}{l}\text { Two third } \\
\text { lysosomes/ } \\
\text { one third } \\
\text { cytosol }\end{array}$ \\
\hline & $\begin{array}{l}\text { Clarithromycin, } \\
\text { roxithromycin }\end{array}$ & Fast & Fast & $10-20$ & \\
\hline & Azithromycin & Fast & $\begin{array}{l}\text { Slow to } \\
\text { very slow }\end{array}$ & $40-300$ & \\
\hline & Telithromycin & Fast & Fast to slow & $15-50$ & \\
\hline Fluoroquinolones & All & $\begin{array}{l}\text { Fast to } \\
\text { very fast }\end{array}$ & Very fast & $4-10$ & Cytosol \\
\hline Aminoglycosides & All & Very slow & Very slow & $\begin{array}{c}2-4 \text { (after } \\
\text { several days) }\end{array}$ & Lysosomes \\
\hline \multirow[t]{2}{*}{ Lincosaminides } & Clindamycin & Fast & Fast & $5-20$ & Unknown \\
\hline & Lincomycin & Fast & Fast & $1-4$ & \\
\hline Tetracyclines & All (?) & Fast & $?$ & $1-4$ & Unknown \\
\hline \multirow{2}{*}{$\begin{array}{l}\text { Ansamycins } \\
\text { (rifamycins) }\end{array}$} & Rifampin & Fast & $?$ & $2-10$ & Unknown \\
\hline & Rifapentin & Fast & $?$ & $60-80$ & \\
\hline \multirow[t]{3}{*}{ Glycopeptides } & Vancomycin & Slow & $?$ & 8 (after $24 \mathrm{~h})$ & $\begin{array}{l}\text { Lysosomes } \\
\text { (in kidney) }\end{array}$ \\
\hline & Teicoplanin & Fast & $?$ & 60 & Unknown \\
\hline & Oritavancin & Slow & Slow & $\begin{array}{l}150-300 \\
\text { (after } 24 \mathrm{~h})\end{array}$ & $\begin{array}{l}\text { Probably } \\
\text { lysosomal }\end{array}$ \\
\hline Oxazolidinones & Linezolid & Fast & Fast & $\sim 1$ & Unknown \\
\hline
\end{tabular}

a very fast: less than 3 min to equilibrium; fast: 3 to 15 min to equilibrium; slow: 15 min to $3 \mathrm{~h}$ to equilibrium; very slow: more than $3 \mathrm{~h}$ to equilibrium.

${ }^{b} \mathrm{C}_{\mathrm{c}} / \mathrm{C}_{\mathrm{E}}$ : accumulation factor (ratio between the cellular concentration and the extracellular concentration).

\section{Macrolides}

In sharp contrast with $\beta$-lactams, macrolides show a marked intracellular accumulation in almost all cells [5,14,15,22-27]. The extent of their accumulation, however, varies markedly among derivatives, with relatively low values for erythromycin and single-base macrolides, to extensive values for those macrolides carrying two basic functions. Overlap has been observed, however, indicating that other parameters are important. Beyond these variations, the common behavior of macrolides can be explained most easily by their character of weak bases, and applying exactly the same modeling as for the weak acids, with the result that the total drug concentration of weak bases must indeed be higher in acidic, membranebounded compartments. One additional factor, however, needs to be taken 
into consideration. Cells contain a fairly acidic compartment, which is the lysosomal apparatus, the volume of which may not exceed $5 \%$ to $10 \%$ of the cell volume but in which the $\mathrm{pH}$ can be as low as 5 [28]. This creates a motive force and a potential for 100-fold accumulation of a single base drug, as compared with the extracellular milieu, to 10,000-fold for a dibasic drug [29]. Consequently, the bulk of the cell-associated macrolides is found in lysosomes and related vacuoles. Collapsing the $\mathrm{pH}$ gradient across the lysosomal and the pericellular membranes abolishes all accumulation [26]. Uptake and efflux of macrolides are generally rapid, with the notable exception of azithromycin, for which binding to cellular structures (mainly the phospholipids [30,31]) could play a critical role. A role of drug transporters with a link to $\mathrm{Ca}_{2}{ }^{+}$channels or a $\mathrm{Ca} 2^{+}$channel-operated mechanism has been advocated for the uptake of macrolides but seems restricted to certain cell types. An efflux transporter modulating the accumulation of macrolides at equilibrium has been evidenced in murine macrophages but affects mainly azithromycin and erythromycin [32].

\section{Fluoroquinolones}

Fluoroquinolones have long been known to accumulate in eucaryotic cells [15,33-40]. The cellular concentrations of fluoroquinolones are generally 4to 10-fold larger than the extracellular. This accumulation is rapid but there is no convincing explanation for its mechanism. A specific transport pathway has been tentatively identified in polymorphonuclear neutrophil leukocytes (PMN) for ciprofloxacin, together with an amino acid transporter activated by phorbol myristate acetate [41]. Uptake could also be regulated by the activation of protein kinase $\mathrm{C}$ and mitogen-activated protein kinase [42]. Yet, simple diffusion followed by loose binding to subcellular constituents cannot be excluded. Efflux of fluoroquinolones is faster than uptake and is probably mediated by an efflux transporter, which can be inhibited by probenecid [43] and has been provisionally identified as an multiple resistance-related protein (MRP) efflux transporter. Cell-associated fluoroquinolones have been consistently recovered in the final supernate after cell fractionation studies $[35,44]$. This can be interpreted in two different ways: efflux from a specific subcellular compartment is fast; or fluoroquinolones are genuinely localized in the cytosol, but probably able to diffuse in the various subcellular compartments as they do through the various organs of the body.

\section{Aminoglycosides}

Aminoglycosides have long been believed not to penetrate in eucaryotic cells. Studies in macrophages and in fibroblasts [45-47], however, have shown that cells incubated for several days in the presence of aminoglycosides accumulate these drugs to an apparent cellular-to-extracellular ratio of 2 to 4 . Further studies demonstrated that intracellular aminoglycosides are almost exclusively sequestered in the lysosomes, which they access for most 
cells through fluid-phase endocytosis [47-49]. This explains their slow rate of accumulation, which led many impatient observers erroneously to conclude about a lack of penetration. Cells displaying surface binding sites, such as kidney proximal tubular cells in vivo, however, accumulate aminoglycosides quite fast and extensively [50,51]. These sites have been identified as megalin (a protein binding polybasic compounds; [52-54]) on the one hand, and acidic phospholipids on the other hand [55].

\section{Other antibiotics}

Much less is known about the other antibiotics. Among the lincosaminides, clindamycin has been notorious for its large cellular accumulation $[9,56]$, which has been ascribed to its basic character (see previous discussion for macrolides) and to the potential activity of a nucleoside transporter [57]. Surprisingly, however, its closely related congener lincomycin is only poorly accumulated by cells. The cellular pharmacokinetics of tetracyclines has not been studied in details, and apart from a few studies [58,59], there is only indirect or partial evidence of their ability to penetrate and accumulate in eucaryotic cells. The mechanisms remain obscure. PMNs incubated with chlortetracyclines have been shown to display a perinuclear fluorescent signal [60], but the data have never been further confirmed and no attempt at further studying the localization of tetracyclines by other techniques has been reported. Among ansamycins, rifampin accumulates from 2- to 10-fold according to the studies [61-63], whereas rifapentine shows a much higher accumulation (up to 60- to 80-fold [64]). The mechanism of this accumulation as well as the subcellular distribution of ansamycins remain, however, unknown. Few studies have dealt with glycopeptides. Vancomycin shows a slow uptake and modest accumulation in macrophages (up to eightfold in 24 hours [65]) and is supposed to accumulate in lysosomes (at least in proximal tubular cells of the kidney after in vivo administration [66]). Conversely, teicoplanin, a more lipophilic compound, shows a more extensive and faster accumulation (40- to 60-fold [64,67]) but its localization is not known. Oritavancin shows an exceptionally high accumulation in murine macrophages (between 150- and 300-fold after 24 hours [65]), and is probably located in lysosomes. Only one study has been published for oxazolidinones, in which linezolid was shown to reach intracellular concentrations only slightly above the extracellular one in PMNs and in McCoy cells [68]. Uptake and efflux are very fast with a maximal concentration reached within 5 minutes and $90 \%$ of the drug being released in less than 2 minutes on transfer to fresh medium.

\section{Intracellular activity of antibiotics (cellular pharmacodynamics)}

There is a massive amount of literature on the intracellular activity of antibiotics and on its relation to cellular accumulation and disposition, 
dealing with a fascinating variety of different models spanning from in vitro to animal and clinical studies and a large number of drugs as can be seen from a series of key reviews over the last 15 years [69-81]. Few original studies, however, have systematically examined the relationship between drug concentration (or dosing); time of exposure (or other pertinent pharmacokinetic parameters); and chemotherapeutic response (in terms of quantitative measurement of the variation in the bacterial population). Moreover, in many experimental studies the extracellular concentrations and the timing of the experiments have often been unrealistically higher or lower than can be observed with patients. An additional difficulty that needs to be underscored is the fact that antibiotics may exert either favorable or unfavorable actions on the host cells, which modulates their activity and must be studied in detail. Quite anxiously, indeed, a recent review noted that "Overall, neutrophil-microbe interactions are complex and difficult to dissect, and carefully designed experiments using closely defined conditions are required if meaningful results are to be obtained" [82]. Clinical studies, in this context, are particularly difficult, because they tend to provide a global answer to what is actually influenced by a combination of complex extracellular and intracellular pharmacokinetic variables, together with another array of microbial and host-responses variables, and the simultaneous presence of extracellular and intracellular foci of infection. This has been evidenced clearly from studies with rifamycins [83], or more broadly speaking on antimycobacterial therapy [84]. All these factors explain why it remains so difficult to delineate the pharmacodynamic properties of antibiotics as far as intracellular activity is concerned, and why so many conflicting views have been expressed in this context. There are still lacking today in the field of intracellular infection the sound, systematic approaches that have been successfully used to determine the pharmacokinetic-pharmacodynamic parameters of antibiotics with respect to the extracellular infections.

There is nevertheless a consensus on the fact that macrolides, fluoroquinolones, tetracyclines, and ansamycins should have an activity against intracellular bacteria (and should be amenable to pharmacodynamic studies) because these drugs have been used successfully to treat a variety of both obligate and facultative intracellular organisms. A key question, however, remains whether this activity is optimal and whether it bears any relationship with the cell accumulation and subcellular disposition properties that have been summarized previously. Conversely, there is more or less also a consensus over the fact that $\beta$-lactams and aminoglycosides show no or only a poor intracellular activity. But here, one faces the realities that most of the in vitro studies supporting such a conclusion used shortterm exposures only, and that $\beta$-lactams are effective in the treatment of listeriosis, and that aminoglycosides have been successfully used for decades for the treatment of tuberculosis. In both cases, a large part of the bacterial inoculum is intracellular. Many other paradoxical situations could be 
discussed, but only add to the confusion if dealt in details without placing the whole issue in a broader perspective.

Actually, some of the paradoxes may become understandable if considering carefully the in vitro results presented for $L$ monocytogenes in Fig. 2 and for Staphylococcus aureus in Fig. 3. In the first model, one sees in the left panel that a fluoroquinolone (moxifloxacin) has essentially the same activity, as function of its extracellular concentration, against intracellular and extracellular bacteria. The paradoxes here are that moxifloxacin is a concentration-dependent antibiotic (like all fluoroquinolones) and is accumulated about sevenfold in the cells where $L$ monocytogenes is multiplying. Moreover, both moxifloxacin and $L$ monocytogenes are in the
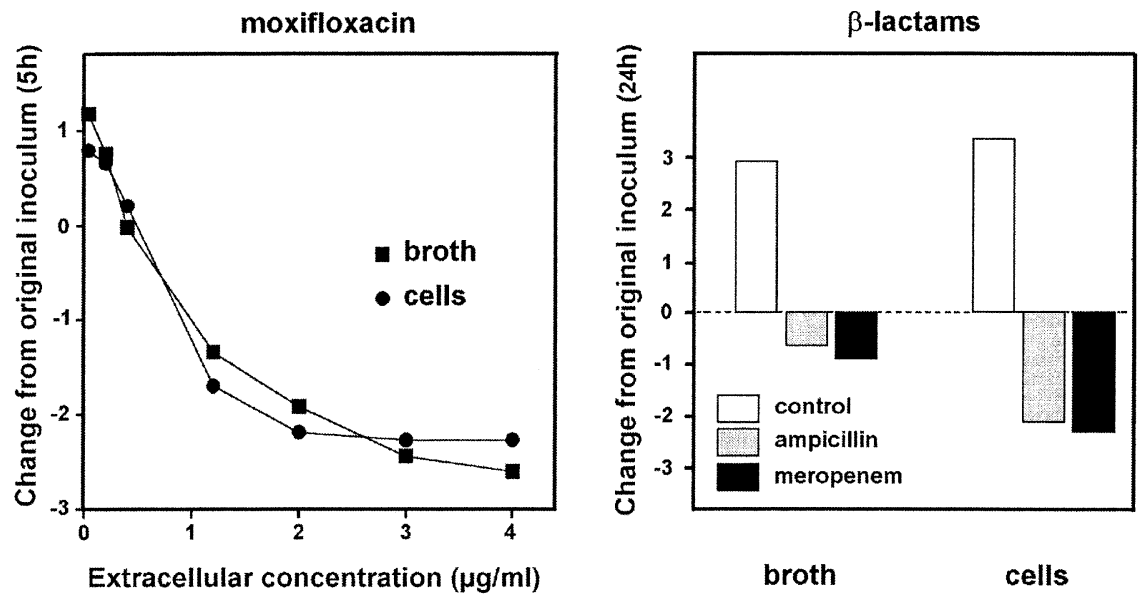

Fig. 2. Evidencing some of the paradoxes in the intracellular activity of antibiotics. The figures show the antibacterial activity of moxifloxacin (left) and $\beta$-lactams (ampicillin, meropenem) against extracellular (broth) and intracellular (cells [THP-1 macrophages]) Listeria monocytogenes. (Left) Influence of an increase in moxifloxacin concentration in broth or in the extracellular milieu on the change in colony-forming units in a 5-h model. The paradox here is that moxifloxacin, which is clearly a concentration-dependent antibiotic, does not act more efficaciously in cells although it accumulates about sevenfold (as determined by both fluorometric and bioassay). This suggests that a large part of the intracellular drug is prevented from acting against Listeria. (From Carryn S, Van Bambeke F, Mingeot-Leclercq MP, Tulkens PM. Comparative intracellular [THP-1 macrophage] and extracellular activities of beta-lactams, azithromycin, gentamicin, and fluoroquinolones against Listeria monocytogenes at clinically relevant concentrations. Antimicrob Agents Chemother 2002;46:2095-103; with permission.) (Right) Antibacterial activity of ampicillin and meropenem (both at $50 \mathrm{mg} / \mathrm{L}$ ) against extracellular (broth) and intracellular (cells [THP-1 macrophages]) L monocytogenes in a 24-h model. The paradox here is that both $\beta$-lactams are more active in cells than in broth, even though they do not accumulate in cells (as determined by bioassay). This is only seen after $24 \mathrm{~h}$, because only little activity is observed in the 5-h model. (Adapted from Carryn S, Van Bambeke F, Mingeot-Leclercq MP, Tulkens PM. Activity of \{beta\}-lactams (ampicillin, meropenem), gentamicin, azithromycin and moxifloxacin against intracellular Listeria monocytogenes in a 24 h THP-1 human macrophage model. J Antimicrob Chemother 2003;51:1051-2; with permission.) 


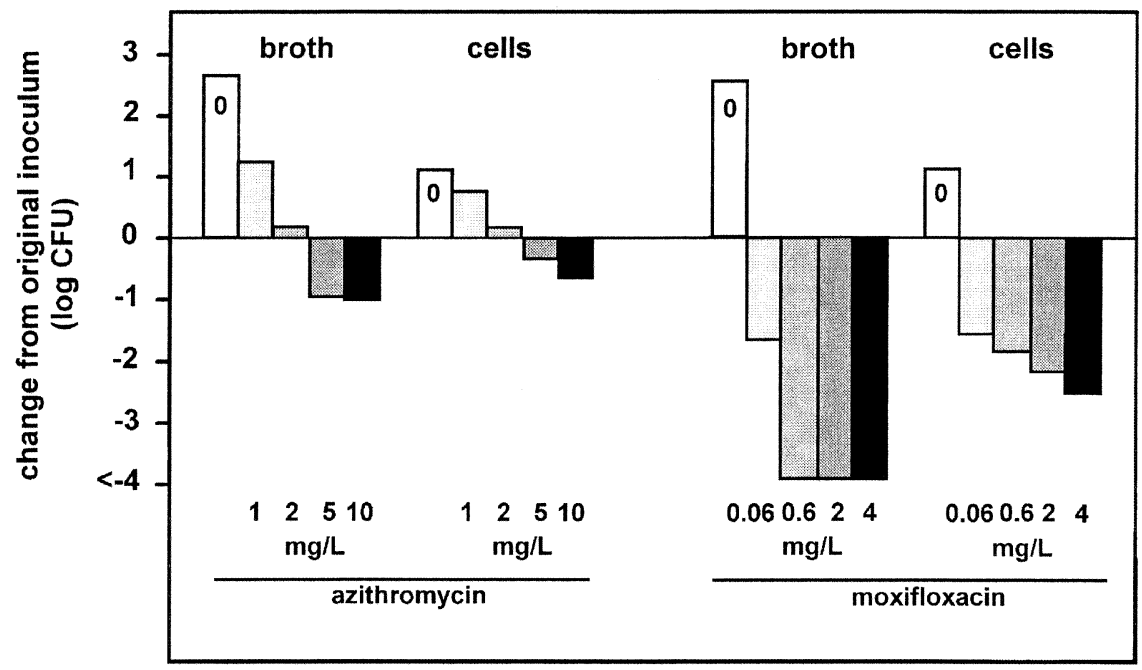

Fig. 3. Evidencing some of the paradoxes in the intracellular activity of antibiotics. The figures show the antibacterial activity of azithromycin (left) and moxifloxacin (right) at increasing concentrations against extracellular (broth) and intracellular (cells [J774 macrophages]) $S$ aureus ( $24 \mathrm{~h}$ model). model; the white bars with a 0 are controls without antibiotic (broth) or with gentamicin (1 X the MIC, to prevent extracellular growth of $S$ aureus; gentamicin is not added when azithromycin or moxiflxoacin are present). The paradox here is that azithromycin, which concentrates about 30 -fold in cells (confirmed by bioassay) and is concentrated in phagolysosomes where $S$ aureus sojourns, is less active intracellularly than extracellularly. In contrast, moxifloxacin, which is less accumulated than azithromycin and does not concentrate in phagolysosomes, shows a definite bactericidal effect against intracellular $S$ aureus. Part of the paradox could be explained by the observation that the MIC and $\mathrm{MBC}$ of azithromycin and moxifloxacin against the strain of $S$ aureus used were $0.5 / 8$ and $0.06 / 0.06$ at $\mathrm{pH} 7$, and 512/512 and $0.25 / 1 \mathrm{mg} / \mathrm{L}$ at $\mathrm{pH} 5$. Note also that the serum concentration of azithromycin in patients does not exceed $0.5 \mathrm{mg} / \mathrm{L}$ suggesting that the drug will be inefficacious in vivo, whereas moxifloxacin may reach a concentration of $4 \mathrm{mg} / \mathrm{L}$, at which it shows a marked activity in this model. (Adapted from Seral C, Van Bambeke F, Tulkens PM. Quantitative analysis of gentamicin, azithromycin, telithromycin, ciprofloxacin, moxifloxacin, and oritavancin (LY333328) activities against intracellular Staphylococcus aureus in mouse $\mathbf{J} 774$ macrophages. Antimicrob Agents Chemother 2003;47:2283-92; with permission.)

cytosol and therefore should be in direct contact. It seems that the activity of moxifloxacin is impaired intracellularly exactly in proportion to its accumulation, which can be considered as self-defeating in this respect. The right panel of Fig. 3 shows that $\beta$-lactams are bactericidal against intracellular Listeria and to almost the same extent than moxifloxacin. The paradoxes here are that neither ampicillin nor meropenem accumulate in cells but their activity is nevertheless larger against the intracellular Listeria than against the extracellular ones; and that the $\beta$-lactams eventually appear almost as active intracellularly as moxifloxacin. There is, however an essential difference between the two models, which is that the second uses a 24-hour incubation time, whereas the first is limited to 5 hours. If the 
incubation with $\beta$-lactams is limited to 5 hours, very little activity is seen $[15,85]$. Thus, the conclusion here is that intracellular fluoroquinolones act rapidly in a concentration-dependent manner but in a limited fashion and in a suboptimal way (interestingly enough, moxifloxacin has been found effective in animal models of listeriosis, but one lacks of clinical data). In contrast, $\beta$-lactams act slowly in a concentration-independent manner (see [15] for detailed dose-dependence studies), but become effective if prolonged contact is obtained. Opposite conclusions contradicting the clinical experience are reached if not for examining the influence of time in this setup.

Fig. 3 illustrates another paradox using the $S$ aureus model and comparing azithromycin and moxifloxacin. The huge accumulation of azithromycin in cells, and its co-localization with $S$ aureus in the phagolysosomes, would make many to predict a large activity. Yet, one sees that azithromycin, at an extracellular concentration of $1 \mathrm{mg} / \mathrm{L}$, is only bacteriostatic against intracellular bacteria (no gain is obtained if moving to the clinically unrealistic extracellular concentration of $10 \mathrm{mg} / \mathrm{L}$ ). This implies that eradication with azithromycin will require host factors (which are not much present in this model). Conversely, moxifloxacin, which is not concentrated in lysosomes and accumulates much less than azithromycin, is clearly bactericidal on a concentration-dependent fashion. Note, however, that as for the Lmonocytogenes model, moxifloxacin is less effective intracellularly than extracellularly. The reasons for these contrasting and apparently paradoxical behaviors are that azithromycin is, in almost all instances, a bacteriostatic antibiotic for which high local concentrations are probably useless per se (although they may ensure a prolonged exposure), whereas the local environment, and especially the acidic $\mathrm{pH}$, which is highly unfavorable to the activity of azithromycin, only slightly affects that of moxifloxacin, a bactericidal drug (about fourfold increase in minimum inhibitory concentration [MIC] at $\mathrm{pH} 5$ versus 7).

These and other similar observations have led the authors to propose the scheme presented in Fig. 4, which illustrates the main parameters that may critically influence the activity of antibiotics against intracellular bacteria (and explains many of the paradoxes and contradictions found in the literature). Table 3 lists the pharmacokinetic-pharmacodynamic properties that can be expected for the main classes of antibiotics in this context. Three aspects need to be underlined. First, most of the basic observations made concerning extracellular infections are observed for intracellular activity. $\beta$ Lactams are time-dependent, whereas fluroquinolones and aminoglycosides are clearly concentration-dependent. For $\beta$-lactams, this definitely justifies prolonged treatments at the maximal dose to compensate for the lack of accumulation and suggests that there is a place for continuous infusion as advocated for in systemic infections [86]. For macrolides, activity is clearly observed against phagosomal organisms (phagosomes are neutral or only slightly acidic), but to a level that has no relationship with their huge 


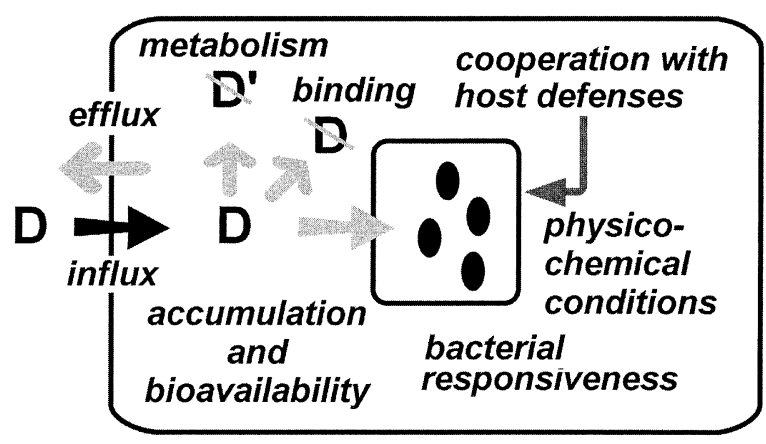

Fig. 4. Factors affecting the intracellular activity of antibiotics. The balance between influx and efflux, metabolism, and binding determines the intracellular concentration of free active drug. The latter must, however, still be able to reach its target (the box is only intended to show that such access may be prevented but does not imply that all bacteria are in membrane-bounded structures). Activity is then influenced by the state of bacterial responsiveness; the physicochemical conditions prevailing at the site of infection; and the degree of cooperation (or hindrance) with the host defenses. As a result, the final outcome may bear only a very remote correlation with the actual extracellular drug concentration and even the degree of cellular concentration. This, however, does not mean that cell penetration and cell concentration are irrelevant because an absence of penetration or an insufficient local concentration can never be associated with activity.

accumulation, probably because of their intrinsically bacteriostatic activity. The goal here probably is to reach a sufficiently high concentration to cope with the loss of activity caused by low $\mathrm{pH}$ or binding to cell constituents, but little gain is expected by further increasing the concentration. The point of a critical concentration should be underlined. Indeed, whereas some organisms, like Chlamydia and Legionella, are quite sensitive, this may not be the case for others, such as $S$ aureus. The importance of a concentration threshold in intracellular activity has been demonstrated recently by the description of clinical failures with Chlamydia showing resistance to concentrations of azithromycin of $4 \mathrm{mg} / \mathrm{L}$ or higher in the BGMK cell assay system [87]. Interestingly enough, an increase in azithromycin accumulation, as obtained by inhibiting its efflux from macrophages, has been shown to decrease the extracellular concentration needed to obtain a bacteriostatic affect in the $S$ aureus $/ \mathbf{J} 774$ macrophage model depicted in Fig. 3 [44]. In contrast to both $\beta$-lactams and macrolides, concentration seems a critical determinant for fluoroquinolones and these antibiotics show typical concentration-dependent efficacy. Because fluoroquinolones also seem to kill fast, time tends to become less important, which suggests that area under the plasma-concentration curve is not a major determinant. One is struck, however, by the impairment of activity, which may make fluoroquinolones ineffective unless a sufficiently high extracellular concentration can be reached. This limitation was already underlined for Listeria $[88,89]$, and may be critical for $S$ aureus if considering methicillin- 
Table 3

Proposed intracellular pharmacodynamic parameters for the main pharmacochemical classes of antibiotics and modulation of activity by the cellular environment

\begin{tabular}{|c|c|c|c|}
\hline $\begin{array}{l}\text { Pharmacochemical } \\
\text { class }\end{array}$ & $\begin{array}{l}\text { Proposed pharmacodynamic } \\
\text { parameter }\end{array}$ & $\begin{array}{l}\text { Modulation by the environment } \\
\text { at the predominant localization in cell }\end{array}$ & $\begin{array}{l}\text { Overall result and expected } \\
\text { clinical implication }\end{array}$ \\
\hline$\beta$-lactams & Time of exposure & Favored (after long exposure) & $\begin{array}{l}\text { Activity remains low but can be } \\
\text { larger than expected for } \\
\text { organisms in cytosol } \\
\text { treatments must be prolonged }\end{array}$ \\
\hline Macrolides & $\begin{array}{l}\text { Critical concentration } \\
\text { (but remain essentially } \\
\text { static; time, therefore, } \\
\text { seems unimportant) }\end{array}$ & $\begin{array}{l}\text { Markedly decreased acidic } \mathrm{pH} \text {; } \\
\text { binding to cellular constituents) }\end{array}$ & $\begin{array}{l}\text { Act on organisms in } \\
\text { phagolysosomes but to } \\
\text { an extent lower than } \\
\text { anticipated }\end{array}$ \\
\hline Fluoroquinolones & $\begin{array}{l}\text { Concentration (but eradication } \\
\text { may not be obtained); act } \\
\text { rapidly so that time may be } \\
\text { unimportant beyond a few hours }\end{array}$ & $\begin{array}{l}\text { Decreased (to an amount equal } \\
\text { or larger than the cellular } \\
\text { accumulation) }\end{array}$ & $\begin{array}{l}\text { Activity depends on the extracellular } \\
\text { concentration; dosing is } \\
\text { probably essential }\end{array}$ \\
\hline Aminoglycosides & $\begin{array}{l}\text { Concentration (but activity } \\
\text { develops slowly because of } \\
\text { the low rate of uptake, } \\
\text { so that time is important) }\end{array}$ & $\begin{array}{l}\text { Severe impairment (acid } \mathrm{pH}) \\
\text { Note: inappropriate subcellular } \\
\text { localization and lack of } \\
\text { diffusion may also be critical }\end{array}$ & $\begin{array}{l}\text { Activity depends on both the } \\
\text { dose and the time of } \\
\text { exposure; prolonged } \\
\text { treatments are required }\end{array}$ \\
\hline \multicolumn{4}{|l|}{ Glycopeptides } \\
\hline Vancomycin & Time & $?$ & $\begin{array}{l}\text { Activity remains low; not } \\
\text { recommended in clinical practice }\end{array}$ \\
\hline Oritavancin & Concentration & Decreased & $\begin{array}{l}\text { Effective but could be restricted } \\
\text { to phagolysosomal organisms }\end{array}$ \\
\hline
\end{tabular}

The list is limited to classes for which sufficient data are available. 
resistant organisms, because those tend to show elevated MIC toward fluoroquinolones. A puzzling observation for fluoroquinolones is also the lack of eradication even when concentrations are increased to several multiples of the MIC. This suggests that part of the inoculum is inaccessible or metabolically insensitive to fluoroquinolones. This has been observed not only with L monocytogenes [15] but also with $S$ aureus [90] and Chlamydia spp. [91] and does not seem to be linked to selection of resistant mutants. It is tempting to speculate that this lack of eradication could be the reason for failure of fluroquinolones with Brucella infection in vivo [92], which is characterized by the maintenance of a residual inoculum from which reinfection is observed. For aminoglycosides, their specific pharmacokinetic properties (ie, a slow uptake) make prolonged treatments essential. Time becomes an important parameter in addition to concentration. A severe impairment of their activity is also noted, which may explain failures under conditions of inappropriate dosing or accumulation time (the low $\mathrm{pH}$ of phagolysosomes is probably responsible for this loss of activity because its neutralization increases activity [93]). Unfortunately, much less can be said about the other antibiotics, with the exception of oritavancin, which has been recently studied but for which more experience is needed. No or very little true pharmacodynamic data are available for ansamycins (including rifampin) or tetracyclines, even though these antibiotics were among the first to be claimed to be active in a variety of intracellular infections [94-98].

\section{Summary}

This article establishes the pharmacokinetic-pharmacodynamic parameters that are important when considering the intracellular activity of antibiotics. Generally speaking, the main classes of antibiotics seem to share globally the same properties against extracellular and intracellular organisms. The specific cellular pharmacokinetic properties may modulate those parameters so as to let other ones to become critical. Simple rules, such as equating accumulation and activity, are certainly incorrect, and other determinants need to be added to the equation. Finally, this article emphasizes the fact that much remains to be done in this area before rational therapeutic choices can be made.

\section{References}

[1] de Duve C. A guided tour of the living cell. New York: Scientific American Books/The Rockefeller University Press; 1984.

[2] Karupiah G, Hunt NH, King NJ, Chaudhri G. NADPH oxidase, Nrampl and nitric oxide synthase 2 in the host antimicrobial response. Rev Immunogenet 2000;2:387-415.

[3] Nathan CF, Hibbs JB Jr. Role of nitric oxide synthesis in macrophage antimicrobial activity. Curr Opin Immunol 1991;3:65-70. 
[4] Portnoy DA, Auerbuch V, Glomski IJ. The cell biology of Listeria monocytogenes infection: the intersection of bacterial pathogenesis and cell-mediated immunity. J Cell Biol 2002;158:409-14.

[5] Ouadrhiri Y, Scorneaux B, Sibille Y, Tulkens PM. Mechanism of the intracellular killing and modulation of antibiotic susceptibility of Listeria monocytogenes in THP-1 macrophages activated by gamma interferon. Antimicrob Agents Chemother 1999;43: $1242-51$.

[6] Alford CE, King TE Jr, Campbell PA. Role of transferrin, transferrin receptors, and iron in macrophage listericidal activity. J Exp Med 1991;174:459-66.

[7] Byrne GI, Lehmann LK, Landry GJ. Induction of tryptophan catabolism is the mechanism for gamma-interferon-mediated inhibition of intracellular Chlamydia psittaci replication in T24 cells. Infect Immun 1986;53:347-51.

[8] Yang D, Biragyn A, Kwak LW, Oppenheim JJ. Mammalian defensins in immunity: more than just microbicidal. Trends Immunol 2002;23:291-6.

[9] Prokesch RC, Hand WL. Antibiotic entry into human polymorphonuclear leukocytes. Antimicrob Agents Chemother 1982;21:373-80.

[10] Forsgren A, Bellahsene A. Antibiotic accumulation in human polymorphonuclear leucocytes and lymphocytes. Scand J Infect Dis Suppl 1985;44:16-23.

[11] Laufen H, Wildfeuer A, Rader K. Uptake of antimicrobial agents by human polymorphonuclear leucocytes. Arzneimittelforschung 1985;35:1097-9.

[12] Jacobs RF, Thompson JW, Kiel DP, Johnson D. Cellular uptake and cell-associated activity of third generation cephalosporins. Pediatr Res 1986;20:909-12.

[13] Renard C, Vanderhaeghe HJ, Claes PJ, Zenebergh A, Tulkens PM. Influence of conversion of penicillin $\mathrm{G}$ into a basic derivative on its accumulation and subcellular localization in cultured macrophages. Antimicrob Agents Chemother 1987;31:410-6.

[14] Mandell GL, Coleman E. Uptake, transport, and delivery of antimicrobial agents by human polymorphonuclear neutrophils. Antimicrob Agents Chemother 2001;45: 1794-8.

[15] Carryn S, Van Bambeke F, Mingeot-Leclercq MP, Tulkens PM. Comparative intracellular (THP-1 macrophage) and extracellular activities of beta-lactams, azithromycin, gentamicin, and fluoroquinolones against Listeria monocytogenes at clinically relevant concentrations. Antimicrob Agents Chemother 2002;46:2095-103.

[16] Nix DE, Goodwin SD, Peloquin CA, Rotella DL, Schentag JJ. Antibiotic tissue penetration and its relevance: models of tissue penetration and their meaning. Antimicrob Agents Chemother 1991;35:1947-52.

[17] Tipper DJ, Strominger JL. Mechanism of action of penicillins: a proposal based on their structural similarity to acyl-D-alanyl-D-alanine. Proc Natl Acad Sci U S A 1965;54: $1133-41$.

[18] Ghuysen JM, Frère JM, Leyh-Bouille M. The D-alanyl-D-Ala peptidases: mechanism of action of penicillins and delta-3-cephalosporins. In: Salton M, Shockman GD, editors. Beta-lactam antibiotics: mode of action, new development, and future prospects. New York: Academic Press; 1981. p. 127-52.

[19] Wilkinson GR. Pharmacokinetics: the dynamics of drugs absorption, distribution and elimination. In: Hardman JG, Limbird LL, editors. Goodman \& Gilman's the pharmacological basis of therapeutics. New York: McGraw Hill Medical Publishing Division; 2001. p. 3-30.

[20] Cao CX, Silverstein SC, Neu HC, Steinberg TH. J774 macrophages secrete antibiotics via organic anion transporters. J Infect Dis 1992;165:322-8.

[21] Van Bambeke F, Michot JM, Tulkens PM. Antibiotic efflux pumps in eukaryotic cells: occurrence and impact on antibiotic cellular pharmacokinetics, pharmacodynamics and toxicodynamics. J Antimicrob Chemother 2003;51:1067-77.

[22] Martin JR, Johnson P, Miller MF. Uptake, accumulation, and egress of erythromycin by tissue culture cells of human origin. Antimicrob Agents Chemother 1985;27:314-9. 
[23] Miller MF, Martin JR, Johnson P, Ulrich JT, Rdzok EJ, Billing P. Erythromycin uptake and accumulation by human polymorphonuclear leukocytes and efficacy of erythromycin in killing ingested Legionella pneumophila. J Infect Dis 1984;149: $714-8$.

[24] Anderson R, Van Rensburg CE, Joone G, Lukey PT. An in-vitro comparison of the intraphagocytic bioactivity of erythromycin and roxithromycin. J Antimicrob Chemother 1987;20(suppl B):57-68.

[25] Carlier MB, Garcia-Luque I, Montenez JP, Tulkens PM, Piret J. Accumulation, release and subcellular localization of azithromycin in phagocytic and non-phagocytic cells in culture. Int J Tissue React 1994;16:211-20.

[26] Tyteca D, Van Der Smissen P, Mettlen M, Van Bambeke F, Tulkens P, Mingeot-Leclercq MP, et al. Azithromycin, a lysosomotropic antibiotic, has distinct effects on fluid-phase and receptor-mediated endocytosis, but does not impair phagocytosis in J774 macrophages. Exp Cell Res 2002;281:86-100.

[27] Tyteca D, Van Der SP, Van Bambeke F, Leys K, Tulkens PM, Courtoy PJ, et al. Azithromycin, a lysosomotropic antibiotic, impairs fluid-phase pinocytosis in cultured fibroblasts. Eur J Cell Biol 2001;80:466-78.

[28] Ohkuma S, Poole B. Fluorescence probe measurement of the intralysosomal pH in living cells and the perturbation of $\mathrm{pH}$ by various agents. Proc Natl Acad Sci U S A 1978; 75:3327-31.

[29] de Duve C, de Barsy T, Poole B, Trouet A, Tulkens P, Van Hoof F. Commentary: lysosomotropic agents. Biochem Pharmacol 1974;23:2495-531.

[30] Montenez JP, Van Bambeke F, Piret J, Brasseur R, Tulkens PM, Mingeot-Leclercq MP. Interactions of macrolide antibiotics (erythromycin A, roxithromycin, erythromycylamine [Dirithromycin], and azithromycin) with phospholipids: computer-aided conformational analysis and studies on acellular and cell culture models. Toxicol Appl Pharmacol 1999;156:129-40.

[31] Van Bambeke F, Gerbaux C, Michot JM, d'Yvoire MB, Montenez JP, Tulkens PM. Lysosomal alterations induced in cultured rat fibroblasts by long-term exposure to low concentrations of azithromycin. J Antimicrob Chemother 1998;42:761-7.

[32] Seral C, Michot JM, Chanteux H, Mingeot-Leclercq MP, Tulkens PM, Van Bambeke F. Influence of P-glycoprotein Inhibitors on the accumulation of macrolides in $\mathbf{J} 774$ murine macrophages. Antimicrob Agents Chemother 2002;47:1047-51.

[33] Easmon CS, Crane JP. Uptake of ciprofloxacin by human neutrophils. J Antimicrob Chemother 1985;16:67-73.

[34] Easmon CS, Crane JP. Uptake of ciprofloxacin by macrophages. J Clin Pathol 1985; 38:442-4.

[35] Carlier MB, Scorneaux B, Zenebergh A, Desnottes JF, Tulkens PM. Cellular uptake, localization and activity of fluoroquinolones in uninfected and infected macrophages. J Antimicrob Chemother 1990;26(suppl B):27-39.

[36] Memin E, Panteix G, Revol A. Is the uptake of pefloxacin in human blood monocytes a simple diffusion process? J Antimicrob Chemother 1996;38:787-98.

[37] Pascual A, Garcia I, Perea EJ. Fluorometric measurement of ofloxacin uptake by human polymorphonuclear leukocytes. Antimicrob Agents Chemother 1989;33:653-6.

[38] Pascual A, Garcia I, Ballesta S, Perea EJ. Uptake and intracellular activity of moxifloxacin in human neutrophils and tissue-cultured epithelial cells. Antimicrob Agents Chemother 1999;43:12-5.

[39] Garcia I, Pascual A, Ballesta S, Joyanes P, Perea EJ. Intracellular penetration and activity of gemifloxacin in human polymorphonuclear leukocytes. Antimicrob Agents Chemother 2000;44:3193-5.

[40] Garcia I, Pascual A, Ballesta S, Perea EJ. Uptake and intracellular activity of ofloxacin isomers in human phagocytic and non-phagocytic cells. Int J Antimicrob Agents 2000; 15:201-5. 
[41] Walters JD, Zhang F, Nakkula RJ. Mechanisms of fluoroquinolone transport by human neutrophils. Antimicrob Agents Chemother 1999;43:2710-5.

[42] Hotta K, Niwa M, Hirota M, Kanamori Y, Matsuno H, Kozawa O, et al. Regulation of fluoroquinolone uptake by human neutrophils: involvement of mitogen-activated protein kinase. J Antimicrob Chemother 2002;49:953-9.

[43] Cao C, Steinberg TH, Neu HC, Cohen D, Horwitz SB, Hickman S, et al. Probenecidresistant $\mathbf{J} 774$ cell expression of enhanced organic anion transport by a mechanism distinct from multidrug resistance. Infect Agents Dis 1993;2:193-200.

[44] Seral C, Carryn S, Tulkens PM, Van Bambeke F. Influence of P-glycoprotein and MRP efflux pump inhibitors on the intracellular activity of azithromycin and ciprofloxacin in macrophages infected by Listeria monocytogenes or Staphylococcus aureus. J Antimicrob Chemother 2003;51:1167-73.

[45] Bonventre PF, Imhoff J. Uptake of ${ }^{3} \mathrm{H}$-dihydrostreptomycin by macrophages in culture. Infect Immun 1970;2:86-93.

[46] Bonventre PF, Hayes R, Imhoff J. Autoradiographic evidence for the impermeability of mouse peritoneal macrophages to titrated streptomycin. J Bacteriol 1967;93:445-50.

[47] Tulkens P, Trouet A. The uptake and intracellular accumulation of aminoglycoside antibiotics in lysosomes of cultured rat fibroblasts. Biochem Pharmacol 1978;27: 415-24.

[48] El Mouedden M, Laurent G, Mingeot-Leclercq MP, Tulkens PM. Gentamicin-induced apoptosis in renal cell lines and embryonic rat fibroblasts. Toxicol Sci 2000;56:229-39.

[49] Ford DM, Dahl RH, Lamp CA, Molitoris BA. Apically and basolaterally internalized aminoglycosides colocalize in LLC-PK1 lysosomes and alter cell function. Am J Physiol 1994;266(1 pt 1):C52-7.

[50] Just M, Erdmann G, Habermann E. The renal handling of polybasic drugs. 1. Gentamicin and aprotinin in intact animals. Naunyn Schmiedebergs Arch Pharmacol 1977;300:57-66.

[51] Silverblatt FJ, Kuehn C. Autoradiography of gentamicin uptake by the rat proximal tubule cell. Kidney Int 1979;15:335-45.

[52] Moestrup SK, Cui S, Vorum H, Bregengard C, Bjorn SE, Norris K, et al. Evidence that epithelial glycoprotein 330/megalin mediates uptake of polybasic drugs. J Clin Invest 1995;96:1404-13.

[53] Nagai J, Tanaka H, Nakanishi N, Murakami T, Takano M. Role of megalin in renal handling of aminoglycosides. Am J Physiol Renal Physiol 2001;281:F337-44.

[54] Schmitz C, Hilpert J, Jacobsen C, Boensch C, Christensen EI, Luft FC, et al. Megalin deficiency offers protection from renal aminoglycoside accumulation. J Biol Chem 2002;277:618-22.

[55] Sastrasinh M, Knauss TC, Weinberg JM, Humes HD. Identification of the aminoglycoside binding site in rat renal brush border membranes. J Pharmacol Exp Ther 1982; 222:350-8.

[56] Easmon CS, Crane JP. Cellular uptake of clindamycin and lincomycin. Br J Exp Pathol 1984;65:725-30.

[57] Hand WL, King-Thompson NL. Membrane transport of clindamycin in alveolar macrophages. Antimicrob Agents Chemother 1982;21:241-7.

[58] Hand WL, Boozer RM, King-Thompson NL. Antibiotic uptake by alveolar macrophages of smokers. Antimicrob Agents Chemother 1985;27:42-5.

[59] Najar I, Oberti J, Teyssier J, Caravano R. Kinetics of the uptake of rifampicin and tetracycline into mouse macrophages: in vitro study of the early stages. Pathol Biol (Paris) 1984;32:85-9.

[60] Coates TD, Torres M, Harman J, Williams V. Localization of chlortetracycline fluorescence in human polymorphonuclear neutrophils. Blood 1987;69:1146-52.

[61] Hoger PH, Vosbeck K, Seger R, Hitzig WH. Uptake, intracellular activity, and influence of rifampin on normal function of polymorphonuclear leukocytes. Antimicrob Agents Chemother 1985;28:667-74. 
[62] Hand WL, Corwin RW, Steinberg TH, Grossman GD. Uptake of antibiotics by human alveolar macrophages. Am Rev Respir Dis 1984;129:933-7.

[63] Johnson JD, Hand WL, Francis JB, King-Thompson N, Corwin RW. Antibiotic uptake by alveolar macrophages. J Lab Clin Med 1980;95:429-39.

[64] Pascual A, Tsukayama D, Kovarik J, Gekker G, Peterson P. Uptake and activity of rifapentine in human peritoneal macrophages and polymorphonuclear leukocytes. Eur $\mathbf{J}$ Clin Microbiol 1987;6:152-7.

[65] Van Bambeke F, Snoeck AS, Chanteux H, Mingeot-Leclercq MP, Tulkens PM. Is LY333328 glycopeptide a new cell-associated antibiotic? Comparative studies with vancomycin and azithromycin in a model of J774 mouse macrophages. Presented at the 11th European Congress of Clinical Microbiology and Infectious Diseases. Istanbul, Turkey, April 1-4, 2001.

[66] Beauchamp D, Gourde P, Simard M, Bergeron MG. Subcellular localization of tobramycin and vancomycin given alone and in combination in proximal tubular cells, determined by immunogold labeling. Antimicrob Agents Chemother 1992;36:2204-10.

[67] Maderazo EG, Breaux SP, Woronick CL, Quintiliani R, Nightingale CH. High teicoplanin uptake by human neutrophils. Chemotherapy 1988;34:248-55.

[68] Pascual A, Ballesta S, Garcia I, Perea EJ. Uptake and intracellular activity of linezolid in human phagocytes and nonphagocytic cells. Antimicrob Agents Chemother 2002;46: 4013-5.

[69] van den Broek PJ. Antimicrobial drugs, microorganisms, and phagocytes. Rev Infect Dis 1989;11:213-45.

[70] Schwab JC, Mandell GL. The importance of penetration of antimicrobial agents into cells. Infect Dis Clin North Am 1989;3:461-7.

[71] Tulkens PM. Intracellular distribution and activity of antibiotics. Eur J Clin Microbiol Infect Dis 1991;10:100-6.

[72] Yancey RJ, Sanchez MS, Ford CW. Activity of antibiotics against Staphylococcus aureus within polymorphonuclear neutrophils. Eur J Clin Microbiol Infect Dis 1991;10:107-13.

[73] van den Broek PJ. Activity of antibiotics against microorganisms ingested by mononuclear phagocytes. Eur J Clin Microbiol Infect Dis 1991;10:114-8.

[74] Pechere JC. Quinolones in intracellular infections. Drugs 1993;45(suppl 3):29-36.

[75] Butts JD. Intracellular concentrations of antibacterial agents and related clinical implications. Clin Pharmacokinet 1994;27:63-84.

[76] Nix DE, Goodwin SD, Peloquin CA, Rotella DL, Schentag JJ. Antibiotic tissue penetration and its relevance: impact of tissue penetration on infection response. Antimicrob Agents Chemother 1991;35:1953-9.

[77] Donowitz GR. Tissue-directed antibiotics and intracellular parasites: complex interaction of phagocytes, pathogens, and drugs. Clin Infect Dis 1994;19:926-30.

[78] Carbon C. Clinical relevance of intracellular and extracellular concentrations of macrolides. Infection 1995;23(suppl 1):S10-4.

[79] Edelstein PH. Review of azithromycin activity against Legionella spp. Pathol Biol (Paris) 1995;43:569-72.

[80] Maurin M, Raoult D. Optimum treatment of intracellular infection. Drugs 1996;52: $45-59$.

[81] Silverstein SC, Kabbash C. Penetration, retention, intracellular localization, and antimicrobial activity of antibiotics within phagocytes. Curr Opin Hematol 1994;1:85-91.

[82] Pallister CJ, Lewis RJ. Effects of antimicrobial drugs on human neutrophil-microbe interactions. Br J Biomed Sci 2000;57:19-27.

[83] Burman WJ, Gallicano K, Peloquin C. Comparative pharmacokinetics and pharmacodynamics of the rifamycin antibacterials. Clin Pharmacokinet 2001;40:327-41.

[84] Burman WJ. The value of in vitro drug activity and pharmacokinetics in predicting the effectiveness of antimycobacterial therapy: a critical review. Am J Med Sci 1997;313: $355-63$. 
[85] Scorneaux B, Ouadrhiri Y, Anzalone G, Tulkens PM. Effect of recombinant human gamma interferon on intracellular activities of antibiotics against Listeria monocytogenes in the human macrophage cell line THP-1. Antimicrob Agents Chemother 1996;40: 1225-30.

[86] Craig WA, Ebert SC. Continuous infusion of beta-lactam antibiotics. Antimicrob Agents Chemother 1992;36:2577-83.

[87] Somani J, Bhullar VB, Workowski KA, Farshy CE, Black CM. Multiple drug-resistant Chlamydia trachomatis associated with clinical treatment failure. J Infect Dis 2000; 181:1421-7.

[88] Michelet C, Avril JL, Cartier F, Berche P. Inhibition of intracellular growth of Listeria monocytogenes by antibiotics. Antimicrob Agents Chemother 1994;38:438-46.

[89] Michelet C, Avril JL, Arvieux C, Jacquelinet C, Vu N, Cartier F. Comparative activities of new fluoroquinolones, alone or in combination with amoxicillin, trimethoprimsulfamethoxazole, or rifampin, against intracellular Listeria monocytogenes. Antimicrob Agents Chemother 1997;41:60-5.

[90] Paillard D, Grellet J, Dubois V, Saux MC, Quentin C. Discrepancy between uptake and intracellular activity of moxifloxacin in a Staphylococcus aureus-human THP-1 monocytic cell model. Antimicrob Agents Chemother 2002;46:288-93.

[91] Kutlin A, Roblin PM, Hammerschlag MR. In vitro activities of azithromycin and ofloxacin against Chlamydia pneumoniae in a continuous-infection model. Antimicrob Agents Chemother 1999;43:2268-72.

[92] Garcia-Rodriguez JA, Garcia Sanchez JE, Trujillano I. Lack of effective bactericidal activity of new quinolones against Brucella spp. Antimicrob Agents Chemother 1991;35:756-9.

[93] Maurin M, Raoult D. Phagolysosomal alkalinization and intracellular killing of Staphylococcus aureus by amikacin. J Infect Dis 1994;169:330-6.

[94] Mandell GL. Staphylococcal infection and leukocyte bactericidal defects in a 22-year-old woman. Arch Intern Med 1972;130:754-7.

[95] Horwitz MA, Silverstein SC. Intracellular multiplication of Legionnaires' disease bacteria (Legionella pneumophila) in human monocytes is reversibly inhibited by erythromycin and rifampin. J Clin Invest 1983;71:15-26.

[96] Vischer WA, Rominger C. Rifampicin against experimental listeriosis in the mouse. Chemotherapy 1978;24:104-11.

[97] Bowie WR, Lee CK, Alexander ER. Prediction of efficacy of antimicrobial agents in treatment of infections due to Chlamydia trachomatis. J Infect Dis 1978;138:655-9.

[98] Yoshida S, Mizuguchi Y, Ohta H, Ogawa M. Effects of tetracyclines on experimental Legionella pneumophila infection in guinea-pigs. J Antimicrob Chemother 1985;16: 199-204.

[99] Kohler S, Porte F, Jubier-Maurin V, Ouahrani-Bettache S, Teyssier J, Liautard JP. The intramacrophagic environment of Brucella suis and bacterial response. Vet Microbiol 2002;90:299-309.

[100] Rockey DD, Scidmore MA, Bannantine JP, Brown WJ. Proteins in the chlamydial inclusion membrane. Microbes Infect 2002;4:333-40.

[101] Ghigo E, Capo C, Tung CH, Raoult D, Gorvel JP, Mege JL. Coxiella burnetii survival in THP-1 monocytes involves the impairment of phagosome maturation: IFN-gamma mediates its restoration and bacterial killing. J Immunol 2002;169:4488-95.

[102] Swanson MS, Fernandez-Moreira E, Fernandez-Moreia E. A microbial strategy to multiply in macrophages: the pregnant pause. Traffic 2002;3:170-7.

[103] Ellis J, Oyston PC, Green M, Titball RW. Tularemia. Clin Microbiol Rev 2002;15:631-46.

[104] Roy CR, Tilney LG. The road less traveled: transport of Legionella to the endoplasmic reticulum. J Cell Biol 2002;158:415-9.

[105] Pieters J. Entry and survival of pathogenic mycobacteria in macrophages. Microbes Infect 2001;3:249-55. 
[106] Van Kirk LS, Hayes SF, Heinzen RA. Ultrastructure of Rickettsia rickettsii actin tails and localization of cytoskeletal proteins. Infect Immun 2000;68:4706-13.

[107] Richter-Dahlfors A, Buchan AM, Finlay BB. Murine salmonellosis studied by confocal microscopy: Salmonella typhimurium resides intracellularly inside macrophages and exerts a cytotoxic effect on phagocytes in vivo. J Exp Med 1997;186:569-80.

[108] Suzuki T, Sasakawa C. Molecular basis of the intracellular spreading of Shigella. Infect Immun 2001;69:5959-66.

[109] Mackaness GB. The phagocytosis and inactivation of staphylococcus by macrophages of normal rabbits. J Exp Med 1960;112:35-53.

[110] Rogers DE, Tompsett R. The survival of staphylococci within human leukocytes. J Exp Med 1952;95:209-30.

[111] Seral C, Van Bambeke F, Tulkens PM. Quantitative analysis of gentamicin, azithromycin, telithromycin, ciprofloxacin, moxifloxacin, and oritavancin (LY333328) activities against intracellular Staphylococcus aureus in mouse J774 macrophages. Antimicrob Agents Chemother 2003;47:2283-92. 